\title{
ЭКОЛОГИЧЕСКАЯ ПСИХИАТРИЯ
}

\author{
УДК 616.8-009.17:616.8-008.6:631.524.824:535.231.16(=1.2)(234.853)
}

Для цитирования: Буртовая Е.Ю., Кантина Т.Э., Литвинчук Е.А. Ретроспективная оценка динамики развития астенического синдрома у подвергшихся облучению жителей населенных пунктов бассейна реки Теча. $\mathrm{Cu}$ бирский вестник психиатрии и наркологии. 2020; 4 (109): 82-87. https://doi.org/10.26617/1810-3111-20204(109)-82-87

\section{Ретроспективная оценка динамики развития астенического синдрома у подвергшихся облучению жителей населенных пунктов бассейна реки Теча}

\section{Буртовая Е.Ю., Кантина Т.Э., Литвинчук Е.А.}

ФГБУН Уральский научно-практический цеентр радиационной медициныл ФМБА России Россия, 454141, Челябинск, ул. Воровского, 68 A

\section{PEЗЮME}

У лиц, подвергшихся радиационному воздействию, как в раннем периоде, так и в более отдаленные сроки наблюдения с высокой частотой выявляется астенический синдром, обусловленный действием радиационного и сопутствующих нерадиационных факторов. Актуальность. Широкое использование атомной энергии в народном хозяйстве, перспективы дальних космических полетов определяют необходимость изучения влияния облучения на состояние центральной нервной системы и развитие астенического синдрома в определенных социально-профессиональных группах населения. Цель. Ретроспективная оценка динамики развития астенического синдрома у подвергшихся воздействию ионизирующего излучения жителей населенных пунктов бассейна реки Теча. Материалы и методы. С использованием данных архивных историй болезни и амбулаторных карт пациентов, наблюдавшихся в клиническом отделении УНПЦ РМ в период с 1950 г. по 2005 г., сформированы две группы исследования, в зависимости от накопленной дозы облучения. В первую группу вошли 100 пациентов, накопленная доза облучения которых превышала 1 Гр. Вторую группу составили 80 пациентов с накопленной дозой облучения не более 0,5 Гр. Полный срок наблюдения был разделен на 11 периодов 5-летней длительности каждый. В каждом временном интервале оценивали клинические данные (невролог, терапевт, психиатр), данные лабораторных и инструментальных (ЭЭГ) исследований. Статистическая обработка результатов выполнялась с использованием пакета прикладных программ Statistica (Ver. 7.0) и MS Excel, с использованием критерия t Стьюдента, критерия $\chi^{2}$ Пирсона, критерия U Манна-Уитни. Различия считали значимыми при $\mathrm{p} \leq 0,05$. Результаты и обсуждение. У пациентов с накопленной дозой облучения более 1 Гр астенический синдром наблюдали не только в раннем периоде после облучения, но и на протяжении всего периода наблюдения с 1950 г. по 2005 г. Частота встречаемости астенического синдрома в первые 20 лет после облучения достигала 60\%, после 30-летнего периода - 50\%, к исходу пятого десятка наблюдения снижалась до $29 \%$ от общего числа обследованных лиц, что свидетельствует о существенных патологических изменениях в функционировании ЦНС облученных лиц. Заключение. Полученные результаты уточняют представление о роли ионизирующего излучения в генезе астенического синдрома.

Ключевые слова: астенический синдром, ионизирующее излучение, атомная промышленность, население, Южный Урал.

\section{ВВЕДЕНИЕ}

Эксплуатация атомных предприятий без адекватной защиты работающего персонала и населения, проживающего на прилегающих к атомным объектам территориях, уже в период становления атомной промышленности (начало 1950-х годов) позволила выявить формирование специфических клинических проявлений, возникающих при длительном воздействии ионизирующего излучения [1]. Медицинское наблюдение за контингентами облученных людей показало ряд последователь- ных системных изменений, прежде всего отмечающихся со стороны гемопоэза и нервнопсихической сферы $[1,2,3,4,5]$. Наиболее ранним проявлением нарушения деятельности центральной нервной системы является астенический синдром $[6,7]$.

\section{ЦЕЛЬ ИССЛЕДОВАНИЯ}

Ретроспективная оценка динамики развития астенического синдрома у подвергшихся облучению жителей населенных пунктов бассейна реки Теча. 
Результаты исследования позволят улучшить понимание развития адаптационных процессов в организме человека при действии ионизирующего излучения, что может быть полезно при оказании медицинской помощи персоналу атомных предприятий, подготовке специалистов к дальним космическим полетам, а также востребовано специалистами организаций, обеспечивающих международное сотрудничество в области обеспечения радиационной безопасности и минимизации медико-биологических эффектов радиационного воздействия на здоровье человека $[8,9]$.

\section{МАТЕРИАЛ И МЕТОДЫ}

Исследование проведено сотрудниками лаборатории экологической патопсихологии. Основой для настоящей работы стали архивные истории болезни стационарных больных, получивших медицинскую помощь в клиническом отделении Уральского научно-практического центра радиационной медицины в период с 1950 г. по 2005 г., и их амбулаторные карты. Также были использованы данные электронного архива медицинских документов отдела База данных «Человек».

На основании этих данных были сформированы две группы исследования. Первую (основную) группу составили жители (100 человек), проживавшие в населенных пунктах бассейна реки Теча с 1949 г. по 1956 г., накопленная доза облучения которых превышала 1 Гр. Средняя доза облучения пациентов первой группы на красный костный мозг составила 1,6 $\pm 0,5$ Гр, доза облучения на мягкие ткани (как аналог облучения головного мозга) в среднем составляла $0,31 \pm 0,01$ Гр. Первая группа в основном была сформирована из женщин $(70 \%)$, славянской этнической принадлежности $(68 \%)$, состоящих в браке $(69 \%)$. Среднее количество обращений за стационарной помощью за период наблюдения (1950-2005 гг.) составило $5,3 \pm 0,7$ раза. Средний возраст на начало наблюдения составил $37,6 \pm 1,3$ года.

Вторую группу (сравнения) (80 человек) составили жители прибрежных сел реки Теча, проживавшие в тот же временной период, как и пациенты первой группы, но доза облучения которых не превышала 1 Гр. Во второй группе средняя доза облучения была статистически значимо ниже $(\mathrm{p}<0,001)$ как на красный костный мозг $0,49 \pm 0,05 \Gamma$ р, так и на мягкие ткани $-0,13 \pm 0,01 \Gamma \mathrm{p}$ по сравнению с первой группой. Во вторую группу, так же как и в первую, преимущественно входили женщины $(67,5 \%)$, славянской этнической принадлежности $(63,7 \%)$, состоящие в браке (60\%). Средний возраст на начало наблюдения во

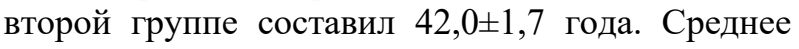
количество обращений за стационарной помощью за период наблюдения (1950-2005 гг.) составило $3,6 \pm 0,7$ раза.
В ходе работы оценивалась динамика клинических проявлений астенического синдрома за период с 1950 г. по 2005 г. в соответствии с результатами клинических осмотров невролога и психиатра, при этом учитывались данные о соматической патологии по результатам осмотра терапевта. Клинические данные дополняли результаты инструментального обследования (электроэнцефалография).

Для проведения анализа динамики развития астенического синдрома срок наблюдения разделили на 11 пятилетних периодов (1950-1955, 1956-1960 гг. и т.Д. вПлоть до 2001-2005 гг.) и оценивали имеющиеся клинические и инструментальные данные за каждый период времени.

Статистическая обработка результатов выполнялась с использованием пакета прикладных программ Statistica (Ver. 7.0) и MS Excell [10, 11]. Данные представлены в виде выборочного среднего (M) и ошибки среднего (m), качественные данные - в виде n, \% (число пациентов с данным признаком, доля их от количества в группе). Для установления значимости различий между группами был использован критерий $\mathrm{t}$ Стьюдента, значимость различий при распределении частот дихотомических показателей оценивалась с помощью критерия $\chi^{2}$ Пирсона. Различия считали значимыми при $\mathrm{p}<0,05$.

\section{РЕЗУЛЬТАТЫ И ОБСУЖДЕНИЕ}

Результаты ретроспективной оценки динамики развития астенического синдрома показали (рис. 1), что у пациентов первой (основной) группы (со статистически значимо более высокой суммарной дозой облучения) частота встречаемости астенического синдрома варьировала от $47 \%$ до $60 \%$ на протяжении 20-летнего периода времени после начала облучения (1950-1970 гг.) и статистически значимо отличалась $(\mathrm{p}<0,001)$ от частоты встречаемости данного синдрома у пациентов второй группы. Клинически, по данным архивных историй болезни и амбулаторных карт, статистически значимо $(\mathrm{p} \leq 0,001)$ у $2 / 3$ пациентов преобладали жалобы на повышенную утомляемость (74\%), усиливавшуюся к концу рабочего дня и выражавшуюся в неспособности справляться с обыденной домашней нагрузкой. Некоторые пациенты ощущали отсутствие сил утром, сразу после пробуждения и нуждались в отдыхе. Статистически значимо $(\mathrm{p}=0,002)$ часто пациенты жаловались на головные боли (76\%), более чем в трети (34\%) случаев имевшие эпизодический характер и усиливающиеся при концентрации внимания и умственном напряжении, а в $42 \%$ случаев - постоянная головная боль. Статистически значимо $(\mathrm{p} \leq 0,001)$ часто при перемене положения тела наблюдалось головокружение $(56 \%)$, в анамнезе отмечались обморочные состояния (12\%). 


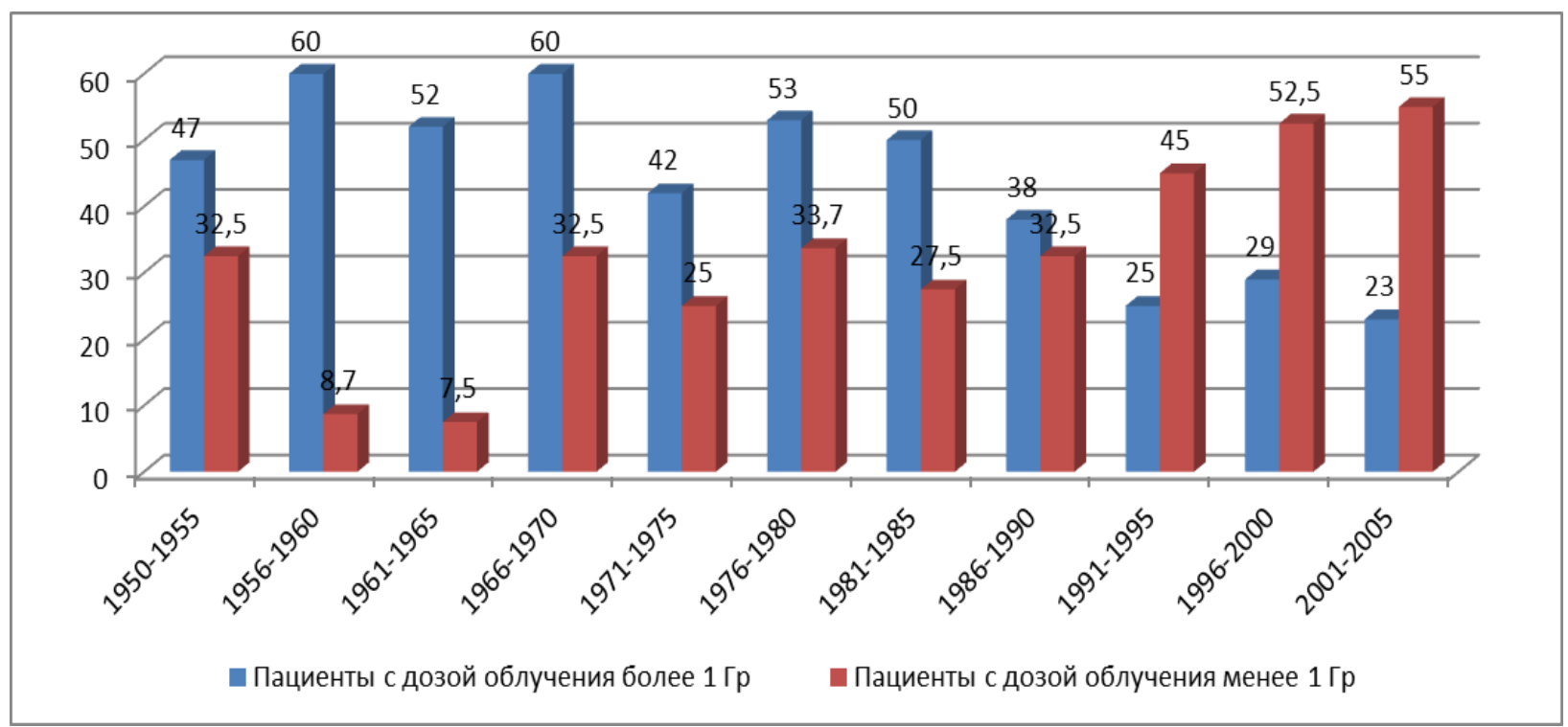

\section{Р и с у н о к 1. Частота встречаемости астенического синдрома у подвергшихся облучению жителей населенных пунктов бассейна реки Теча (\%)}

Более чем у трети (38\%) пациентов наблюдали различные нарушения сна: чуткий, поверхностный, прерывистый сон, некоторые отмечали дневную сонливость или сонливость днем и бессонницу в ночное время. В клинической картине астенического синдромы имели место раздражительность (28\%), повышенная потливость (18\%), нарушение аппетита (45\%), мышечные и суставные боли $(82 \%)$. Большое количество разнообразных жалоб в эти периоды не сопровождалось достаточным объемом объективной информации: наблюдались гипергидроз ладоней (12\%), повышение сухожильных рефлексов (6\%). Пониженные показатели систолического и диастолического артериального давления с тенденцией к гипотонии статистически значимо $(p=0,01)$ чаще встречались у пациентов первой группы по сравнению с пациентами второй группы.

В последующих шести пятилетних периодах (c 1971 г. по 1990 г.) прогрессирующего роста астенической симптоматики не наблюдалось. Частота встречаемости астенического синдрома в первой (основной) группе пациентов колебалась от 53\% до 38\% и к 1990 г. статистически не отличалась от такового показателя во второй группе пациентов (с дозой облучения менее 1 Гр) 32,5\%. В период с 1991 г. по 2005 г. отмечалось снижение частоты астенического синдрома у пациентов первой группы (до 23\%). При этом в клинико-синдромальной структуре повышается частота головной боли $(97 \%)$, головокружений (87\%), шума в ушах (71\%), метеочувствительности и метеозависимости (46\%), нарушений сна $(38 \%)$ и, напротив, практически исчезают жалобы на избыточную потливость $(3 \%)$, но возрастает число жалоб по поводу развивающегося когнитивного снижения (ухудшение памяти на текущие события, трудность длительной концентрации внимания). Вместе с тем средние показатели артериального давления в этом периоде в первой группе по-прежнему статистически значимо $(\mathrm{p}=0,01)$ превышали таковые показатели во второй группе: $162 \pm 8,4$ и 92,1 $\pm 4,1$ мм рт.ст. против $141,3 \pm 7,4$ и 80,2 $\pm 4,3$ мм рт.ст. При неврологическом осмотре отмечалась рассеянная неврологическая симптоматика в виде вегетативнососудистых нарушений. Сопутствующая соматическая патология в большинстве случаев была представлена гипертонической болезнью (89\%) и дисциркуляторной энцефалопатией (63\%). По результатам электроэнцефалографического исследования наблюдался дезорганизованный тип ЭЭГ, с умеренными нарушениями биоэлектрической активности головного мозга по органическому типу.

У пациентов второй группы (с дозой облучения менее 1 Гр) динамика развития астенического синдрома имела существенные отличия. Так в первое пятилетие (1951-1955 гг.) астенический синдром наблюдали у 32,5\% обследованных лиц, в последующие два пятилетия (1956-1965 гг.) произошло существенное снижение данной патологии до $8,7 \%$ от общей доли пациентов второй группы. В дальнейшем отмечается постепенное увеличение частоты астенического синдрома (до $38,7 \%$ в 1976-1980 гг. и 45\% в 1990-1995 гг.). В период 1996-2005 гг. во второй группе (сравнения) сохраняется тренд увеличения частоты астенического синдрома. 
Следует отметить, что в обеих сравниваемых группах жителей населенных пунктов бассейна реки Теча в отдаленном периоде после радиационного воздействия (спустя 30 и более лет) астенический синдром был обусловлен сопутствующей сосудистой патологией в виде вегетососудистой дистонии и сосудистых кризов. Об этом свидетельствовали зафиксированные в медицинской документации данные объективного осмотра и результаты клинических, лабораторных и инструментальных исследований.

Литературные данные, посвященные исследованию влияния ионизирующего излучения на центральную нервную систему (ЦНС), указывают, что в основе выявляемых нарушений находятся сложные нейродинамические сдвиги, возникающие в высших, промежуточных и отчасти средних отделах ЦНС $[1,2]$. В развитии астенического синдрома определяющая роль отводится нарушениям вегетативных и обменных функций организма, ведущим к ослаблению корковой деятельности в регуляции тормозного и возбудительного процессов с преобладанием запредельного торможения и активации структур лимбической системы $[1,4,6]$. В результате происходит снижение функциональной активности нервной системы вследствие истощения адаптационных возможностей. Постепенно, в условиях пролонгированного облучения, формируются микроорганические повреждения ЦНС, в основе которых лежат микронекротические диффузные изменения миелиновых оболочек нервов и дистрофические изменения в ганглиях $[1,4]$. Не менее важным процессом является поражение сосудистого русла на фоне продолжающегося облучения в виде уменьшения плотности капилляров, апоптоза эндотелиальных клеток в связи с низкой способностью организма к компенсаторной пролиферации, так как кровеносные сосуды относятся к тканям с низким пролиферативным потенциалом $[1,4]$.

\section{ЗАКЛЮЧЕНИЕ}

Таким образом, по итогам ретроспективной оценки динамики развития астенического синдрома в двух сравниваемых группах исследовательской выборки подвергшихся облучению жителей населенных пунктов бассейна реки Теча можно констатировать, что его клинические проявления отмечаются с начального периода радиационного облучения, отличаются стойкостью на фоне проводимых лечебных и реабилитационных мероприятий и продолжают определяться даже спустя 30 и более лет после облучения.

\section{КОНФЛИКТ ИНТЕРЕСОВ}

Авторы заявляют об отсутствии явных и потенциальных конфликтов интересов в связи с публикацией данной статьи.

\section{ИСТОЧНИК ФИНАНСИРОВАНИЯ}

Работа выполнена в рамках прикладной НИР «Клинико-биологические характеристики астенического синдрома у лиц, подвергшихся аварийному облучению, в отдаленном периоде после радиационного воздействия».

\section{СООТВЕТСТВИЕ ПРИНЦИПАМ ЭТИКИ}

Исследование соответствует этическим стандартам Хельсинской декларации ВМА и одобрено локальным этическим комитетом ФГБУН УНПЦ РМ ФМБА России (протокол № 1 от 23.01.2017 г.).

\section{ЛИТЕРАТУРА}

1. Аклеев А.В. Хронический лучевой синдром у жителей прибрежных сел реки Теча. Челябинск: Книга, 2012: 464.

2. Аклеев А.В. Экологические и медицинские последствия радиационной аварии 1957 года на ПО «Маяк» / Научные редакторы А.В. Аклеев, М.Ф. Киселев. М. : Медбиоэкстрем, 2001: 294.

3. Рудницкий В.А., Никитина В.Б., Аксенов М.М., Гарганеева Н.П. Экологическая, пограничная и социальная психиатрия: методологические подходы. Тюменский медицинский журнал. 2014; 16(1): 55-59.

4. Отчет МКРЗ по тканевым реакциям, ранним и отдаленным эффектам в нормальных тканях и органах - пороговые дозы для тканевых реакций в контексте радиационной защиты / Ф.А. Стюарт и др.; ред.: А.В. Аклеев, М.Ф. Киселев; пер. с англ.: Е.М. Жидкова, Н.С. Котова. Челябинск: Книга, 2012: 384.

5. Рудницкий В.А., Счастный Е.Д., Никитина В.Б., Костин А.К., Бохан Н.А., Аксенов М.М., Гребенюк О.В., Кибардина А.С., Голощапов С.И. Экологическая психиатрия: проблемы становления и роста, клинические варианты, связи со смежными психиатрическими дисциплинами (клинической, биологической, социальной психиатрией и наркологией). Сибирский вестник психиатрии и наркологии. 2015; 1 (86): 43-50.

6. Буртовая Е.Ю., Кантина Т.Э., Аклеев А.В. Характеристика астенической патологии у лиц, подвергшихся хроническому радиационному воздействию. Академический журнал Западной Сибири. 2014; 10, 5 (54): 51-52.

7. Чекин С.Ю., Кащеев В.В., Карпенко С.В., Ловачёв С.С., Щукина Н.В., Иванов В.К. Группы риска по классу болезней «Психические расстройства и расстройства поведения» среди участников ликвидации последствий аварии на Чернобыльской АЭС, проживающих в Калужской области. Радиация и риск. 2017; 26(1): 2334. DOI: 10.21870/0131-3878-2017-26-1-23-34

8. Буртовой М.Ю., Екимов И.П. Принципы международно-правового регулирования международных отношений в сфере использования атомной энергии. Новое слово в науке: перспективы развития. 2016; 1-2(7):346-347. 
9. Буртовой М.Ю. Генезис международного регулирования сотрудничества государств в сфере энергетических ресурсов. Вестник ЮжноУральского государственного университета. Серия: Право. 2019; 19(2): 42-47. DOI: $10.14529 /$ law 190207.

10. Реброва О.Ю. Статистический анализ медицинских данных. Применение пакета прикладных программ STATISTICA. М.: МедиаСфера, 2000: 312.
11. Трухачева Н.В. Математическая статистика в медико-биологических исследованиях с применением пакета Statistica. М.: ГЭОТАР-Медиа, 2012: 384 .

Поступила в редакцию 02.10.2020

Утверждена к печати 30.11.2020

Буртовая Елена Юрьевна, кандидат медицинских наук, заведующая лабораторией экологической патопсихологии, ФГБУН Уральский научно-практический центр радиационной медицины ФМБА России. SPIN-код 3996-3121. Researcher ID AAW-5440-2020. Author ID 682575. ORCID iD 0000-0002-1260-7745.

Кантина Татьяна Эдуардовна, младший научный сотрудник лаборатории экологической патопсихологии, ФГБУН Уральский научно-практический центр радиационной медицины ФМБА России. SPIN-код 1173-3756. Researcher ID V-6939-2017. Author ID 725164. ORCID iD 0000-0001-6001-4111. e-mail: rejven@ yandex.ru

Литвинчук Елена Александровна, младший научный сотрудник лаборатории экологической патопсихологии, ФГБУН Уральский научно-практический центр радиационной медицины ФМБА России. SPIN-код 7641-7388. Researcher ID V-6928-2017. Author ID 879314. ORCID iD 0000-0003-0061-7134. e-mail: lea22121971@mail.ru

Буртовая Елена Юрьевна, eburtovaya@gmail.com

UDC 616.8-009.17:616.8-008.6:631.524.824:535.231.16(=1.2)(234.853)

For citation: Burtovaia E.Yu., Kantina T.E., Litvinchuk E.A. Retrospective estimation of the dynamics of asthenic syndrome development in exposed residents of settlements in the Techa river basin. Siberian Herald of Psychiatry and Addiction Psychiatry. 2020; 4 (109): 82-87. https://doi.org/10.26617/1810-3111-2020-4(109)-82-87

\section{Retrospective estimation of the dynamics of asthenic syndrome development in exposed residents of settlements in the Techa river basin}

\section{Burtovaia E.Yu., Kantina T.E., Litvinchuk E.A.}

FSGFIS Urals Research Center for Radiation Medicine of Federal Medical Biological Agency of Russia Vorovsky Street 68 A, 454141, Chelyabinsk, Russian Federation

\footnotetext{
ABSTRACT

In persons exposed to radiation, both in the early period and in the more distant periods of observation, asthenic syndrome is detected with a high frequency due to the action of radiation and related non-radiation factors. Background. The widespread use of atomic energy in the national economy, the prospects for long-range space flights determine the need to study the effect of radiation on the state of the central nervous system and the development of asthenic syndrome in certain social and professional groups of the population. Objective. Retrospective estimation of the dynamics of the development of asthenic syndrome in residents of the settlements of the Techa river basin exposed to ionizing radiation. Materials and Methods. Using the data of the archival case histories and outpatient records of patients observed in the clinical department of the USPC RM in the period from 1950 to 2005 , two study groups were formed, depending on the accumulated radiation dose. The first group included 100 patients whose cumulative radiation dose exceeded 1 gray. The second group consisted of 80 patients with an accumulated radiation dose of no more than $0.5 \mathrm{~Gy}$. The total follow-up was divided into 11 periods of 5 years each. In each time interval, clinical data (neurologist, therapist, psychiatrist), laboratory and instrumental (EEG) studies were assessed. Statistical processing of the results was performed using the Statistica (Ver. 7.0) and MS Excel software package, using Student's t test, Pearson's $\chi^{2}$ test, and Mann-Whitney U test. Differences were considered significant at $p \leq 0.05$. Results and Discussion. In patients with the cumulative radiation dose of more than $1 \mathrm{~Gy}$, asthenic syndrome was observed not only in the early period after irradiation, but throughout the entire observation period from 1950 to 2005 . The frequency of its occurrence in the first 20 years after irradiation reached $60 \%$, after 30 -years period - 50\%, by the end of the fifth decade of observation decreased to $29 \%$ of the total number of examined persons, which indicates significant pathological changes in the functioning of the central nervous system of exposed persons. Conclusion. The results obtained clarify the idea of the role of ionizing radiation in the genesis of asthenic syndrome.
} 
Keywords: asthenic syndrome, ionizing radiation, nuclear industry, population, South Urals.

\section{REFERENCES}

1. Akleev A.V. Chronic radiation syndrome in residents of riverside villages of the Techa River. Chelyabinsk: Kniga Publishing House, 2012: 464 (in Russian).

2. Akleev A.V. Ecological and medical consequences of the 1957 radiation accident at Mayak PA. / A.V. Akleev, M.F. Kiselev, eds. Moscow: Publishing House Medbioextrem, 2001: 294 (in Russian).

3. Rudnitsky V.A., Nikitina V.B., Aksenov M.M., Garganeeva N.P. Ecological, borderline and social psychiatry: methodological approaches. Tyumen Medical Journal. 2014; 16(1): 55-59 (in Russian).

4. The report IRPA on tissue reactions, early and remote effects in normal tissues and organs - threshold dose for tissue reaction in the context of radiation protection / F. Stewart and others; ed.: A.V. Akleev, M.F. Kiselev; per. from English: E.M. Zhidkova, N.S. Kotova. Chelyabinsk: Kniga Publishing House, 2012: 384 (in Russian).

5. Rudnitsky V.A., Schastnyy E.D., Nikitina V.B., Kostin A.K., Bokhan N.A., Axenov M.M., Grebenyuk O.V., Kibardina A.S., Goloshchapov S.I. Ecological psychiatry: problems of formation and growth, clinical variants, connections with related psychiatric disciplines (clinical, biological, social psychiatry and addiction psychiatry). Siberian Herald of Psychiatry and Addiction Psychiatry. 2015; 1 (86): 43-50 (in Russian).

6. Burtovaia E.Yu., Kantina T.E., Akleev A.V. Characteristics of asthenic pathology in persons exposed to chronic radiation exposure. Academic Journal of
Western Siberia. 2014; 10, 5 (54): 51-52 (in Russian).

7. Chekin S.Yu., Kashcheev V.V., Karpenko S.V., Lovachev S.S., Shchukina N.V., Ivanov V.K. Risk groups by the class of diseases "Mental and behavioral disorders" among the participants in the liquidation of the consequences of the accident at the Chernobyl nuclear power plant, living in the Kaluga region. Radiation and Risk. 2017; 26(1): 23-34 (in Russian). DOI: 10.21870/0131-3878-2017-26-123-34

8. Burtovoj M.Yu., Yekimov I.P. Principles of international legal regulation of international relations in the sphere of atomic energy use. New Word in Science: Development Prospects. 2016; 1-2(7):346347 (in Russian).

9. Burtovoj M.Yu. Genesis of international regulation of cooperation of states in the field of energy resources. Bulletin of the South Ural State University. Series Law. 2019; 19(2): 42-47 (in Russian). DOI: $10.14529 /$ law190207.

10. Rebrova O.Yu. Statistical analysis of medical data. Application of the STATISTICA application package. Moscow: Publishing House MediaSfera, 2000: 312 (in Russian).

11. Trukhacheva N.V. Mathematical statistics in biomedical research using the Statistica package. Moscow: Publishing House GEOTAR-Media, 2012: 384 (in Russian).

Received October 02.2020

Accepted November 30.2020

Burtovaia Elena Yu., PhD., Head of the Laboratory of Ecological Pathopsychology, Ural Scientific and Practical Center of Radiation Medicine of Federal Biomedical Agency of Russia, Chelyabinsk, Russian Federation. SPIN-code 3996-3121. Researcher ID AAW-5440-2020. Author ID 682575. ORCID iD 0000-0002-1260-7745.

Kantina Tatyana E., junior researcher of the Laboratory of Ecological Pathopsychology, Ural Scientific and Practical Center of Radiation Medicine of Federal Biomedical Agency of Russia, Chelyabinsk, Russian Federation. SPIN-code 1173-3756. Researcher ID V-6939-2017. Author ID 725164. ORCID iD 0000-0001-6001-4111.

e-mail: rejven@yandex.ru

Litvinchuk Elena A., junior researcher of the Laboratory of Ecological Pathopsychology, Ural Scientific and Practical Center of Radiation Medicine of Federal Biomedical Agency of Russia, Chelyabinsk, Russian Federation. SPIN-code 7641-7388. Researcher ID V-6928-2017. Author ID 879314. ORCID iD 0000-0003-0061-7134.

Burtovaia Elena Yu., eburtovaya@gmail.com 